\title{
Analysis of the impact of quick charge technology on the charging process parameters of the lithium-ion storage at various temperatures
}

\author{
Damian Burzyński ${ }^{1, *}$, Damian Głuchy ${ }^{1}$, Maksymilian Godek ${ }^{1}$ \\ ${ }^{1}$ Poznan University of Technology, ul. Piotrowo 3A, 60-965 Poznan, Poland
}

\begin{abstract}
The paper deals with the subject of influence of the Quick Charge technology on the parameters of the charging process of lithium-ion cells. Tests of lithium-ion cell parameters during the charging process were performed at three different temperatures using conventional and accelerated charging. Also, the following paper comprises conclusions related to the conducted tests.
\end{abstract}

\section{Introduction}

The rapid technological development observed in recent years forces the analysis and creation of new solutions in the field of electricity storage [1-3]. It is the reason for the increase in energy consumption of mobile devices which prompts their producers to take actions aimed at preventing energy shortages. One example of such efforts is the development of quick battery charge technologies, which relatively contributes to the longer life of a device on a single charge[4].

\section{Quick charge technology}

In order to supply a bigger amount of energy to a device in a shorter time, the manufacturers provide the energy based on one of two standards available on the market. First of them only assumes an increase in the value of current and the other one links the changes in current with the changes in voltage with temperature. At present, the Quick Charge technology requires the application of appropriate modules in power supplies and receivers, closely cooperating with one another. At the same time, the power supplies and the chargers provided with this technology remain neutral towards devices which do not support this standard, acting at the same time like conventional chargers. Currently, Quick Charge in the 3.0 version is the most common variety of this technology and as well as the option of an increase in the value of current and voltage, it has the INOV (Intelligent Negotiation for Optimal Voltage) technology implemented in the charging algorithm. The adaptive control algorithm, depending on the surrounding conditions, adjusts the amount of the transmitted energy through a change in voltage in the range between 3.2 and $20 \mathrm{~V}$ with a step of $0.2 \mathrm{~V}$ including the appropriate adaptation of the value of current where the maximum possible value obtained by the charger is $3 \mathrm{~A}$. Thankfully to INOV technology, during the charging process that uses Quick Charge 3.0 the power source as well as the device which is being charged are communicating with each other in real time. This increases the life of such a system and decreases the heat losses.

\section{Testing a lithium-ion cell during the charging process using the Quick Charge technology}

The Quick Charge 3.0 technology delivered by the Qualcomm company was subjected to tests. The technology is based on the possibility of free voltage and current control by the core of the operating system and the power supply source suitably prepared for this purpose.

The testing involved the use of the Sony Xperia X Compact smartphone, provided with the Quick Charge 3.0 technology and QNOVO (an optimisation which serves the purpose of extension of the battery life through the proper control algorithm). The battery in the tested device had the rated voltage equal to $3.8 \mathrm{~V}$ and the rated capacity equal to $2700 \mathrm{mAh}$. Each time, before proceeding with the measurements, the tested device was discharged. The charging process consisted of six measuring series: utilizing a conventional charger $(5 \mathrm{~V})$ and a charger that uses the Quick Charge 3.0 technology, for temperatures equal to $5^{\circ} \mathrm{C}, 20^{\circ} \mathrm{C}$ and $40^{\circ} \mathrm{C}$.

\subsection{Test results}

The values of the measured voltages and currents during the charging process were used to determine the momentary power correlated with the changes in the cell temperature. The values of measurements and calculations were presented in figure 1 . 



Fig. 1. Power (a) and temperature (b) versus time in the charging process, with the use of the Quick Charge technology and conventional charging, for three ambient temperatures.

\subsection{Analysis of the obtained results}

Using the Quick Charge technology in a comparison to conventional method of charging shortens the charging time by $22 \%\left(20^{\circ} \mathrm{C}\right), 12 \%\left(40^{\circ} \mathrm{C}\right)$ and $10 \%$ $\left(5^{\circ} \mathrm{C}\right)$. At the same time, the applied technology caused an increase in temperature by $5^{\circ} \mathrm{C}$ in comparison with the conventional charging for measurements at $20^{\circ} \mathrm{C}$. At $40^{\circ} \mathrm{C}$, the difference amounted to $1^{\circ} \mathrm{C}$, and in $5^{\circ} \mathrm{C}$ the difference was $3.5^{\circ} \mathrm{C}$. It is possible to notice that at higher ambient temperature, the temperature difference between the two methods of charging is smaller and is caused by the limitation of power consumption which, in turn, is the direct consequence of the limitation in power consumption through a smartphone. At the same time this resulted in the longer charging time. On the other hand, at $5^{\circ} \mathrm{C}$ the charging time was increased as well in comparison to the ambient temperature equal to $20^{\circ} \mathrm{C}$. Although, that the charging process increased the smartphone's temperature - which was unfavorably low for the device - it limited the energy flow comming from the charger in purpose of protecting the internal battery. Despite the fact that each charging time in $20^{\circ} \mathrm{C}$ in comparison to the ones in $5^{\circ} \mathrm{C}$ are different by almost a mere $5 \%$, in case of a use of Quick Charge technology charging times differ by $17 \%$.

The applied technology, in order to maintain the constant power level reaching the device, during the reduction in voltage by the above-mentioned system, forced an increase in the value of current which reached the battery. Such an activity directly contributes to an increase in the temperature during the charging process.

Quick Charge in cooperation with the charged devices, allows for a reduction in the temperature increase in order to avoid the battery damage, however in conditions where ambient temperature is significantly lowered it prevents the battery from being charged with unreasonably high charging currents in unfavourable conditions. Despite the limitation of power consumption throughout Quick Charge technology in various temperatures, in each of the cases a speed up of the charging process was noticed.

\section{Summary}

Increased voltage and current values during the charging process of mobile devices result in an unavoidable reduction of the lifespan of lithium-ion cells. Intelligent algorithms included in the Quick Charge technology allow for the smooth adjustment of charging parameters in such a manner as to make the charge of the device safe, efficient and faster than in the case of the conventional charge without significant disadvantage to the battery life. The Quick Charge technology leads to a compromise between the life and the battery charge time. Through the communication of the power supply source with the receiver, the optimization which led to an increase in the charging process efficiency was possible.

\section{References}

1. D. Burzyński, L. Kasprzyk, E3S Web of Conferences, 14 (2017)

2. L. Kasprzyk, Prz. Elektrotech. 88, 7B (2012)

3. D. Sbordone, I. Bertini, B. di Pietra, M.C. Falvo, A. Genovese, L. Martirano, Electric Power Systems Research 120 (2015)

4. D. Burzyński, D. Głuchy D, M. Godek, Pozn. Univ. Technol. Acad. J. Electr. Eng. 95, 309-320 (2018)

Corresponding author: damian.burzynski@put.poznan.pl 